\title{
Dual-Band On-Body Repeater Antenna for In-on-On WBAN Applications
}

\author{
Jinpil Tak, Kyeol Kwon, Sunwoo Kim, and Jaehoon Choi \\ Department of Electronics and Communications Engineering, Hanyang University, 17 Haengdang-dong, Seongdong-gu, \\ Seoul 133-791, Republic of Korea
}

Correspondence should be addressed to Jaehoon Choi; choijh@hanyang.ac.kr

Received 24 June 2013; Revised 4 October 2013; Accepted 7 October 2013

Academic Editor: Panagiotis Kosmas

Copyright (C) 2013 Jinpil Tak et al. This is an open access article distributed under the Creative Commons Attribution License, which permits unrestricted use, distribution, and reproduction in any medium, provided the original work is properly cited.

A dual-band on-body repeater antenna for in-on-on wireless body area network applications is proposed. The proposed antenna has a maximum radiation normal to the human-body surface for communication with implanted devices in the $5.8 \mathrm{GHz}$ industrial, scientific, and medical (ISM) band. In addition, to transmit the biological information received from the implanted devices to other on-body devices, the proposed antenna was designed to have a monopole-like radiation pattern along the surface of the human body for communication in the $2.45 \mathrm{GHz}$ ISM band. The antenna was fabricated, and its performance was measured by attaching it to a human-equivalent semisolid phantom. In addition, the human-body effect was studied to ensure antenna performance under an actual situation.

\section{Introduction}

Owing to their variety of potential medical applications, wireless body area networks (WBAN) have received much attention. Medical implants for treatment, diagnosis, and monitoring have been studied in conjunction with the WBAN. For example, a biomedical self-monitoring system for implanted devices can be designed using the WBAN concept. For WBAN communication, the transmitter and receiver can be located in three regions: in-body, on-body, and off-body $[1,2]$. However, the antennas of implanted devices usually have extremely low radiation efficiency because of the body effect. Therefore, establishing a direct communication link between the implanted antennas and antennas for on-body self-monitoring is difficult. To communicate effectively, the signals must be collected from the implanted devices and transmitted to the on-body selfmonitoring devices using repeater systems, as shown in Figure 1. Therefore, the radiation characteristic of a WBAN antenna is an important factor that determines the overall performance of a system [3]. To achieve adequate performance, the field distribution of an antenna for a repeater system must be concentrated toward the human body to collect signals from the implanted devices at one frequency and along the human-body surface to transmit these signals to the self-monitoring devices at another frequency. Thus, a directional radiation pattern toward the in-body direction is essential for on-body to in-body communication link. On the other hand, for proper communication link between two on-body transceivers, the antenna should generate omnidirectional field propagation along the body surface like a vertical monopole $[4,5]$. However, a vertical monopole antenna is not suitable for on-body application because of the height. Therefore, the on-body to on-body communication requires a low-profile antenna with a monopole-like radiation pattern. To generate this monopole-like radiation pattern, various antenna types have been proposed [6-14]. A compact patch antenna with a vertical ground wall and a shorting wall was proposed in [6]. A planar inverted$\mathrm{F}$ antenna using a shorting wall on a two-third muscleequivalent arm phantom was published in [7]. Inspired by the design in [8], a higher mode $\left(\mathrm{TM}_{21}\right)$ microstrip patch antenna (HMMPA) was introduced in [9]. Further, other higher mode $\left(\mathrm{TM}_{01}\right.$ and $\left.\mathrm{TM}_{02}\right)$ circular patch antennas using shorting vias and coupled annular-ring patch were proposed in $[10,11]$. To achieve broadband monopole-type radiation, a half-hemispherical dielectric resonator was suggested in [12]. Surface-wave antennas using via-less electromagnetic 


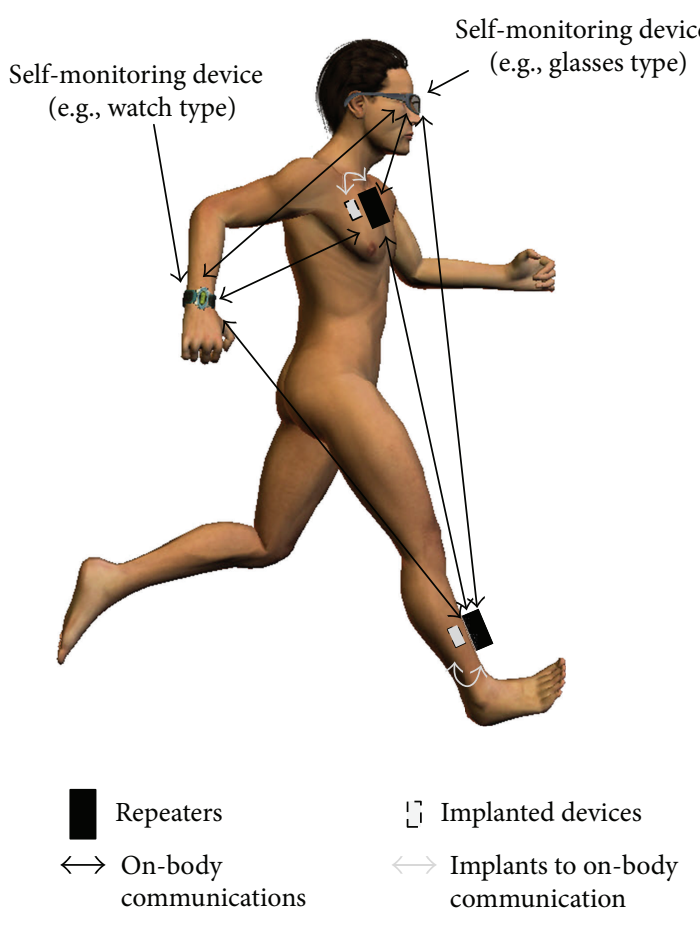

FIgURE 1: Configuration of the proposed antenna.

band-gap materials were introduced for low vertical size in $[13,14]$. However, these antennas still have large horizontal size and are not suitable as repeater antennas because they do not provide the dual radiation performance required in the repeater system. Dual-band or dual-mode antennas for WBAN application were proposed in [15-17]. In [15], a dualband antenna with a dual radiation pattern was proposed. A monoband antenna with a dual pattern was proposed in [16]. However, these antennas have dual- and triple-port systems. The dual-port system antenna for the dual mode or the triple-port system antenna for the triple mode has less novelty in terms of antenna design architecture. In addition, the multiport system is not suitable for miniaturization and integration with the devices. The proposed antenna in [17] has a broadside radiation characteristic, which is not suitable for on-body communication, including the on-body sensor network.

In this paper, a dual-band on-body repeater antenna for in-on-on WBAN applications is proposed. This proposed antenna operates in the $2.45 \mathrm{GHz}$ industrial, scientific, and medical (ISM) band and the $5.8 \mathrm{GHz}$ ISM band. For a oneport repeater system, the proposed antenna has a monopolelike radiation characteristic for on-on communication in the $2.45 \mathrm{GHz}$ ISM band and a broadside radiation for inon communication in the $5.8 \mathrm{GHz}$ ISM band with a low profile. Although the use of the $5.8 \mathrm{GHz}$ ISM band for in-on communication is unconventional by generally considering skin depth and attenuation, this frequency can be used to communicate with a low-depth implantable device such as a pacemaker implanted in the subcutaneous fat (in the near-field region). An implanted microstrip patch antenna is adopted for verification of the in-on communication in the

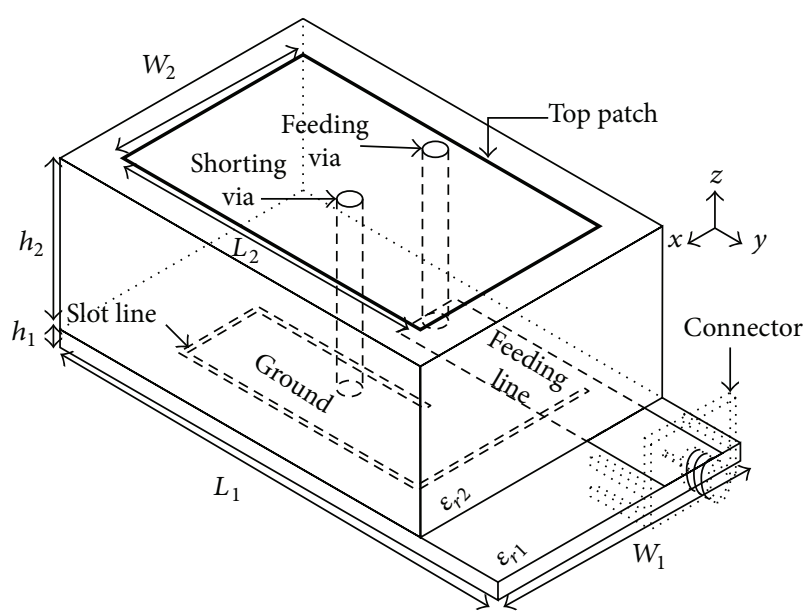

(a)

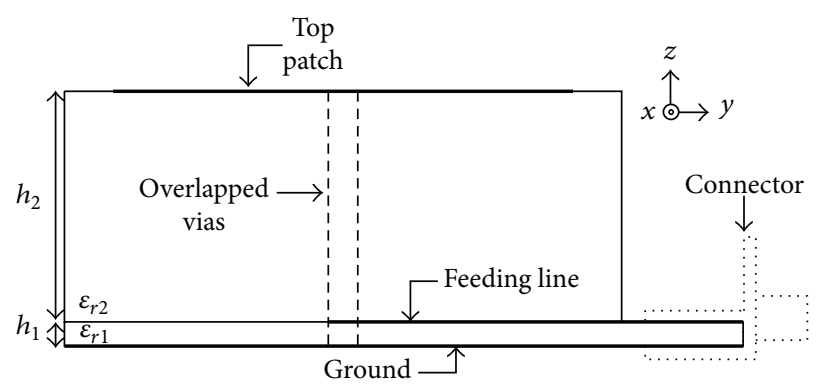

(b)

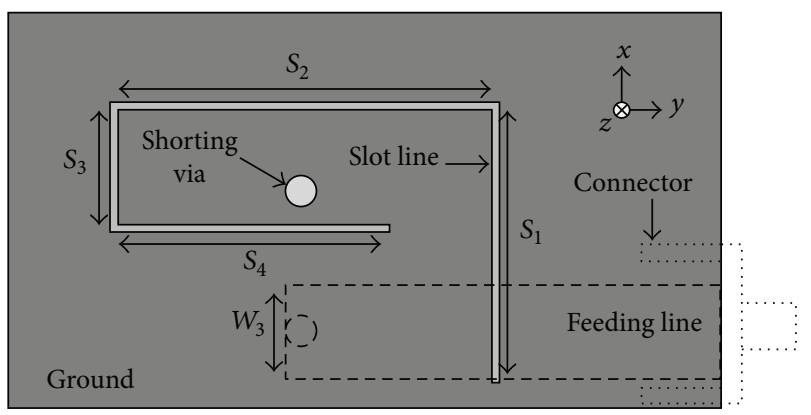

(c)

FIGURE 2: Geometry of the repeater antenna. (a) Isometric view. (b) Side view. (c) Bottom view. The parameters of the proposed antenna are $W_{1}=15.5 \mathrm{~mm}, W_{2}=11.5 \mathrm{~mm}, W_{3}=3.7 \mathrm{~mm}, L_{1}=28 \mathrm{~mm}, L_{2}=$ $19 \mathrm{~mm}, h_{1}=1 \mathrm{~mm}, h_{2}=9.5 \mathrm{~mm}, \varepsilon_{r 1}=2.33, \varepsilon_{r 2}=2.33, S_{1}=11 \mathrm{~mm}, S_{2}$ $=15.3 \mathrm{~mm}, S_{3}=5.1 \mathrm{~mm}$, and $S_{4}=11 \mathrm{~mm}$.

5.8 GHz ISM band. Moreover, a two-third muscle-equivalent human-body phantom is used to analyze the antenna performance.

\section{Antenna Design and Simulation Result}

The geometry of the repeater antenna for the in-on-on WBAN application is shown in Figures 2(a)-2(c). The proposed antenna has a dimension of $L_{1} \times W_{1} \times\left[h_{1}+h_{2}\right.$ $(10.5 \mathrm{~mm})]$ and consists of a top patch fed through a $9.5 \mathrm{~mm}$ 


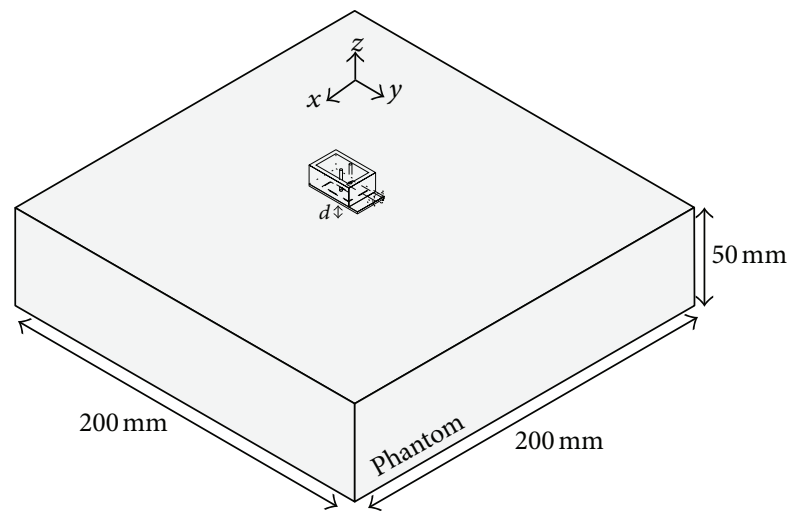

FIGURE 3: Simulation setup for the proposed antenna on a phantom.

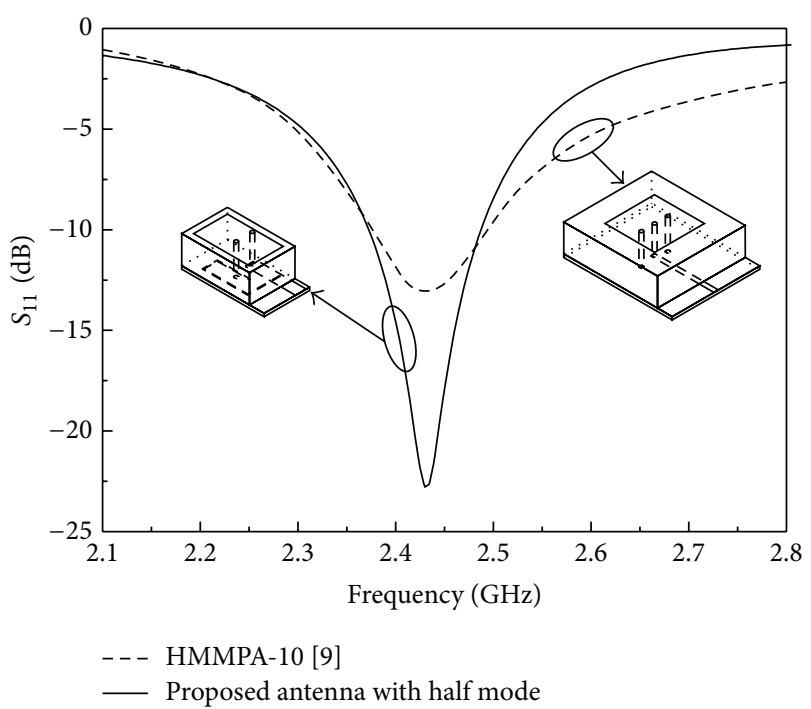

FIGURE 4: Simulated $S$-parameter comparison of the proposed antenna with HMMPA-10 [9].

via connected to a microstrip line and a bottom ground slot fed by a microstrip line on a dielectric substrate with $\varepsilon_{r}=2.33$ and $\tan \delta=0.0009$ (Taconic TLY-3). The radius of the two vias is $0.6 \mathrm{~mm}$.

The proposed antenna was placed $d \mathrm{~mm}$ away from the surface of the cuboid-shaped two-third muscleequivalent phantom $(200 \mathrm{~mm} \times 200 \mathrm{~mm} \times 50 \mathrm{~mm})$ to analyze the dual-band antenna performance, as shown in Figure 3 [18].

The top patch with a shorting via structure was designed for on-body to on-body communications at the $2.45 \mathrm{GHz}$ ISM band, as shown in Figures 2(a) and 2(b). The top patch with the shorting via was fed by a feeding via, which was connected to the microstrip feeding line on the ground plane. To maximize the radiation along the body surface for the on-body to on-body communications and to minimize offbody radiation, an HMMPA with a $\mathrm{TM}_{21}$ mode was adopted [9]. The basic configuration of the HMMPA is a monopolar wire-patch antenna with a monopole-like radiation pattern,

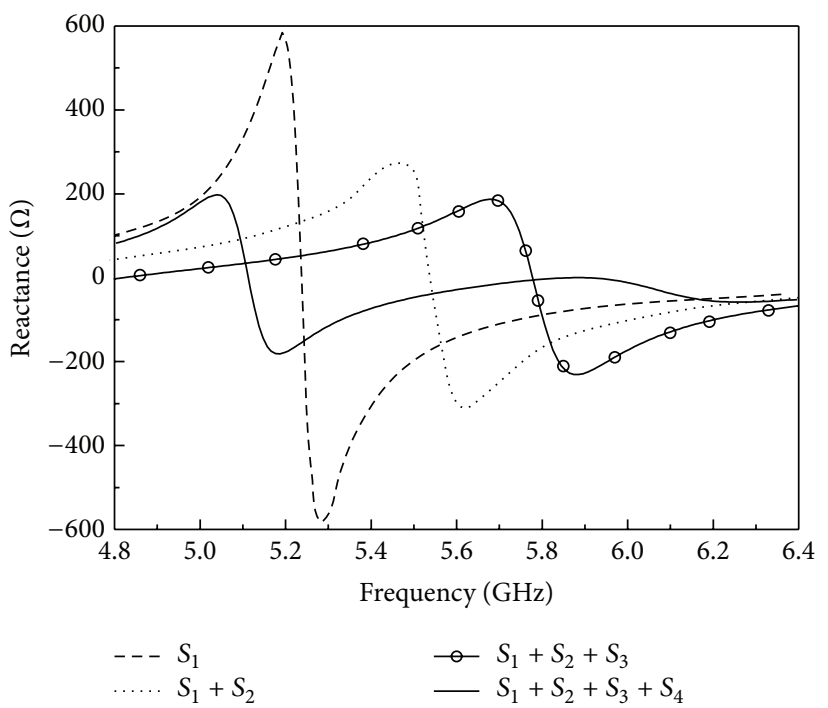

(a)

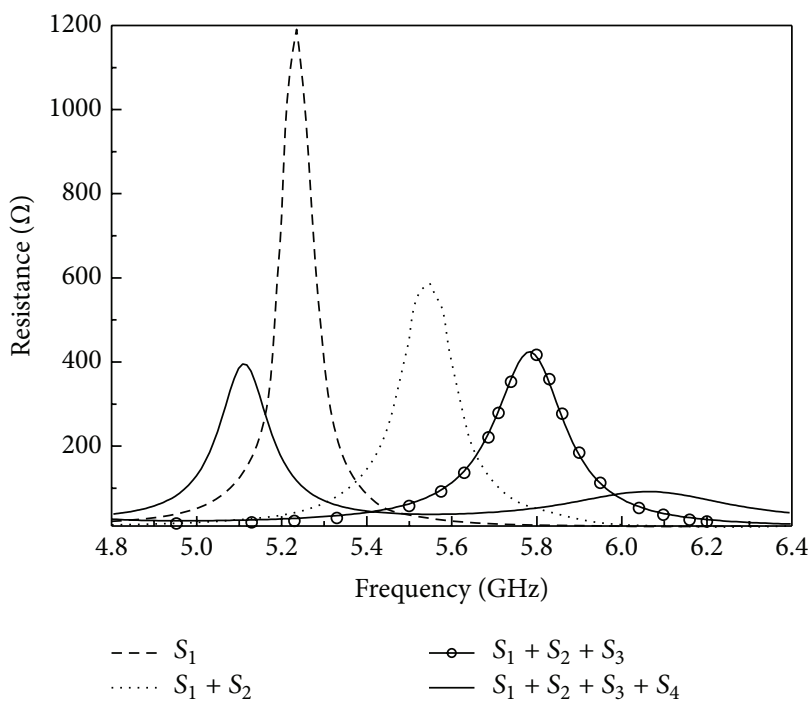

(b)

Figure 5: Effect of the offset slot length on the input impedance characteristics of the slot antenna. (a) Reactance. (b) Resistance.

which was introduced in [8]. Because of the enforced null point of the electric fields on the top patch, which originally has a fundamental $\mathrm{TM}_{11}$ mode generated using a $9.5 \mathrm{~mm}$ shorting via, a higher resonant mode was excited. Even though the proposed antenna is inspired from HMMPA-10 of [9], we miniaturized the antenna size without changing the resonance frequency, resonance mode, and radiation pattern by cutting the $y z$-plane of the HMMPA by half, as shown in Figure 4 [19].

Figure 2(c) shows the bottom view of the proposed antenna. To obtain a directional radiation characteristic for the implanted device at the $5.8 \mathrm{GHz}$ ISM band, a slot at the bottom ground with a width of $0.3 \mathrm{~mm}$, which is excited by an offset microstrip coupled feed, is designed. Increasing the slot length of the bottom plane reduces the input impedance 


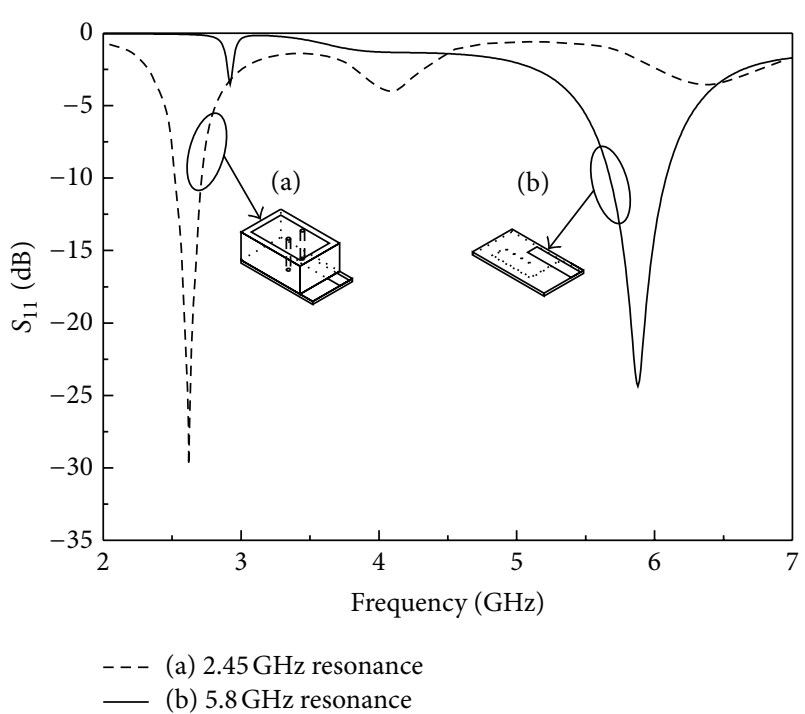

FIGURE 6: Radiating mechanism of the proposed antenna on the phantom. (a) $2.45 \mathrm{GHz}$ ISM band. (b) $5.8 \mathrm{GHz}$ ISM band.

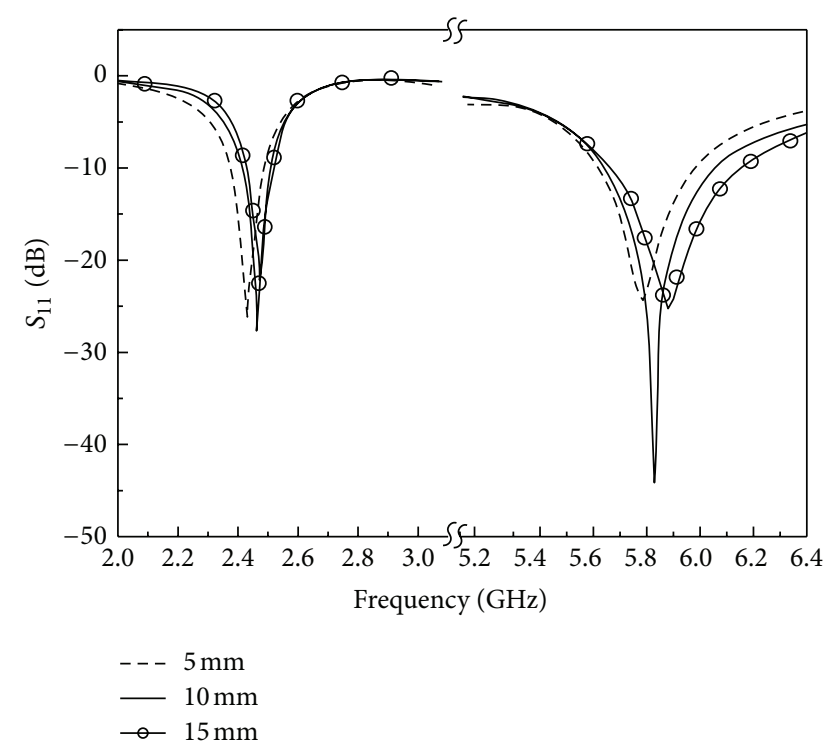

FIgURE 7: Comparison of the simulated $S_{11}$ for various gap distances between the antenna and the phantom.

of the slot antenna, as shown in Figure 5. Therefore, achieving impedance matching is possible by controlling the overall slot length $\left(S_{1}+S_{2}+S_{3}+S_{4}\right)$ [20]. In our design, the slot line is optimized as a P-shape to miniaturize the antenna.

Figure 6 shows the radiation mechanism of the proposed antenna. The proposed antenna has only a single radiator. The radiating mechanism of this antenna is described as follows. (a) At $2.45 \mathrm{GHz}$, the top patch is excited by a via connected to the microstrip feeding line. This shorted top patch operates in the half-TM $\mathrm{TM}_{21}$ mode. (b) At $5.8 \mathrm{GHz}$, the slot line in the ground plane is excited by the microstrip feeding line, and the radiating element is coupled to the slot line.

Figure 7 shows the simulated $S_{11}$ characteristics of the proposed antenna for various gap distances $(d)$ between the antenna and the phantom. The simulated $10 \mathrm{~dB}$ impedance bandwidths of the antenna at $d=10 \mathrm{~mm}$ were $4.5 \%$ (2.4$2.51 \mathrm{GHz})$ at the $2.45 \mathrm{GHz}$ ISM band and $7.2 \%$ (5.62$6.04 \mathrm{GHz}$ ) at the $5.8 \mathrm{GHz}$ ISM band.

In this research, we adopted the two-third muscleequivalent phantom, which is simple, while having the same human-body effects as the three-layer phantom. Figure 8(a) shows that the permittivity and conductivity values of the sixsided two-third muscle-equivalent phantom are two-thirds those of the dispersive muscle; meanwhile, the three-layer phantom is composed of dispersive skin, fat, and muscle according to [18]. Figure 8 (b) shows that the two results are almost the same.

Figures $9(\mathrm{a})$ and $9(\mathrm{~b})$ show the simulated electric-field distributions in the $y z$-plane at $d=10 \mathrm{~mm}$. The proposed antenna has a monopole-like electric-field distribution, which is desirable for on-body surface communication at the $2.45 \mathrm{GHz}$ ISM band (Figure 9(a)), whereas the electric fields are strongly distributed toward the phantom surface at the $5.8 \mathrm{GHz}$ ISM band (Figure 9(b)), which is a desirable property for implants for on-body communication.

Figure 10 shows the simulated current distribution on the top patch of the proposed antenna at $2.45 \mathrm{GHz}$. Assuming that no variation occurs along the $z$-axis, the current varies by one cycle along the $x$-direction and by onehalf cycle along the $y$-direction, showing that the mode excitation on the patch is in a higher order mode $\left(\mathrm{TM}_{21}\right)$ at $2.45 \mathrm{GHz}$.

The simulated far-field radiation patterns of the proposed antenna for various gap distances $(d)$ in the $x z$ - and $y z$-planes are shown in Figure 11. As the gap increases (as $d$ increases), the radiated field becomes slightly stronger because of the decreasing absorption into the phantom. In the $y z$-plane, the maximum simulated gain is $2 \mathrm{dBi}$. The radiation pattern of the proposed antenna is similar to that of a monopole in the $2.45 \mathrm{GHz}$ ISM band.

Figures 12 and 13, respectively, show the isometric view of the simulation setup and the $S$-parameter characteristics of the in-on communication between the implanted microstrip patch antenna in the phantom and the proposed antenna on the phantom. The implanted microstrip patch antenna is designed with a patch size of $12 \mathrm{~mm} \times 12 \mathrm{~mm}$ on an FR-4 epoxy substrate with a dimension of $40 \mathrm{~mm} \times 40 \mathrm{~mm} \times 1 \mathrm{~mm}$ $\left(\varepsilon_{r}=4.4\right.$ and $\left.\tan \delta=0.02\right)$ and to operate in the $5.8 \mathrm{GHz}$ ISM band. Considering practical implanted applications such as pacemakers, the implanted depth from the phantom surface (i) is $5 \mathrm{~mm}$, and the gap between the proposed antenna and the phantom surface $(d)$ is $10 \mathrm{~mm}$. To prevent direct contact between the patch and the phantom, an air-gap insulation of $1 \mathrm{~mm}$ is adopted. Figure 13 shows that the proposed antenna is properly designed for in-on communications in the $5.8 \mathrm{GHz}$ ISM band.

To evaluate the performance of the proposed antenna in a practical environment, a Duke anatomical human model is 


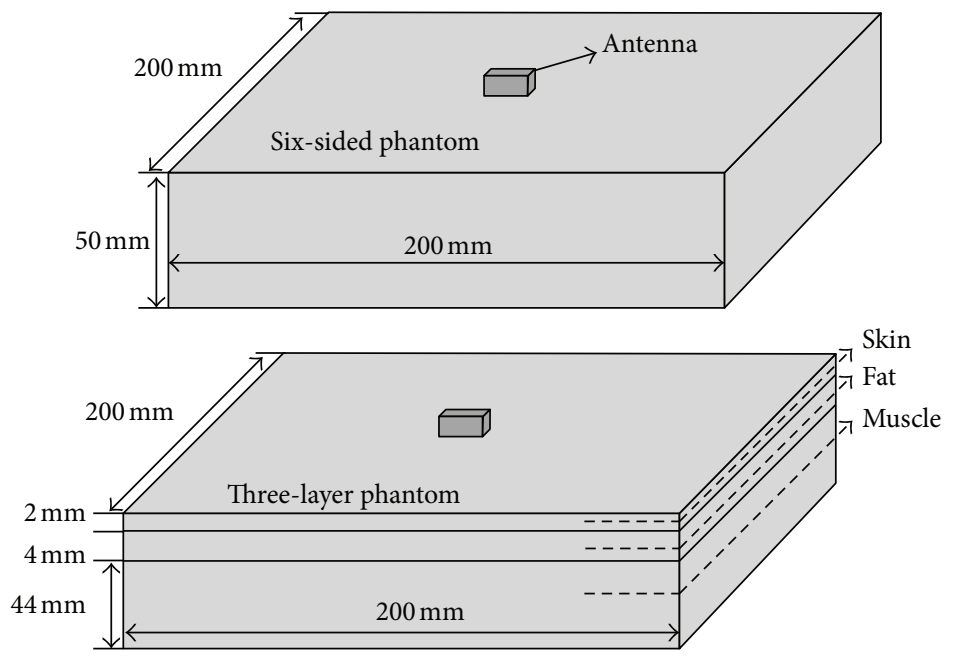

(a)

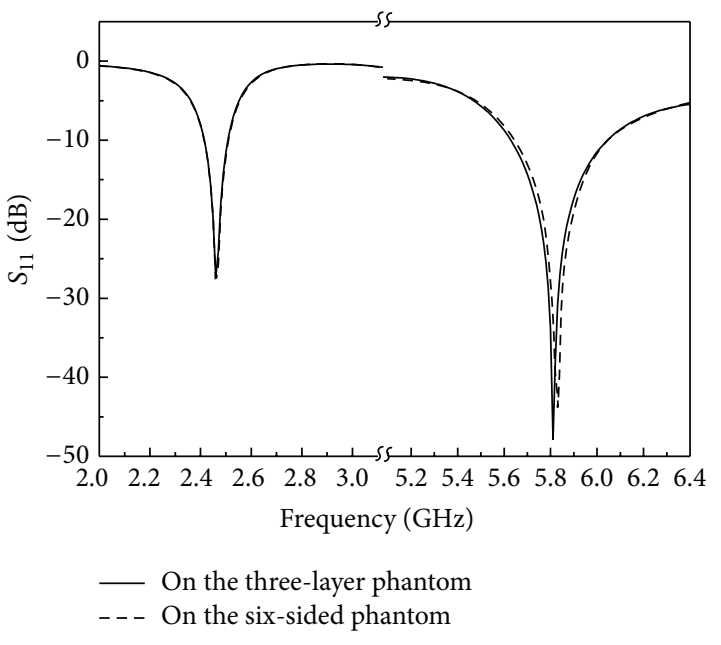

(b)

FIGURE 8: Comparison of the two phantom models. (a) Structure of the two phantom models. (b) Simulated $S_{11}$ characteristics of the two phantom models.

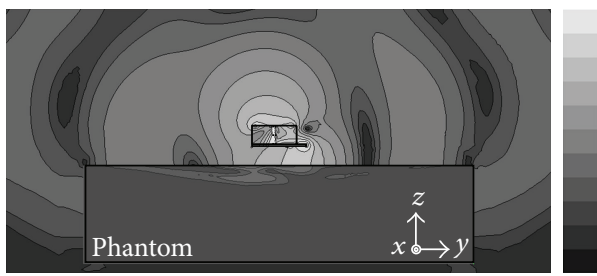

$2.0000 e+003$ $1.1990 e+003$ $7.1876 e+002$ 尺 $4.3089 e+002$ $2.5831 e+002 \succeq$ $1.5485 e+002$ 드 $9.2832 e+001$ $5.5651 e+001$ $3.3362 e+001$ $2.0000 e+001$

(a)

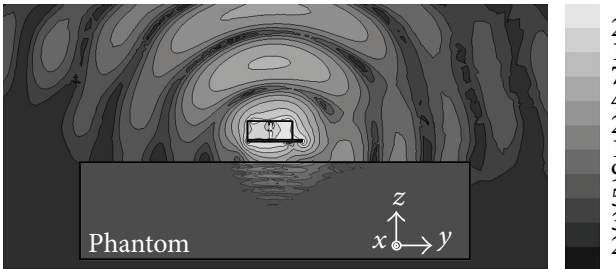

$2.0000 e+003$ $1.1990 e+003$ $7.1876 e+002$ 天 $4.3089 e+002$ $2.5831 e+002$ $1.5485 e+002$ 므 $9.2832 e+001$ $5.5651 e+001$ $5.5651 e+001$ $2.0000 e+001$

(b)

FIGURE 9: Simulated electric-field distribution of the proposed antenna. (a) $2.45 \mathrm{GHz}$ ISM band. (b) $5.8 \mathrm{GHz}$ ISM band.

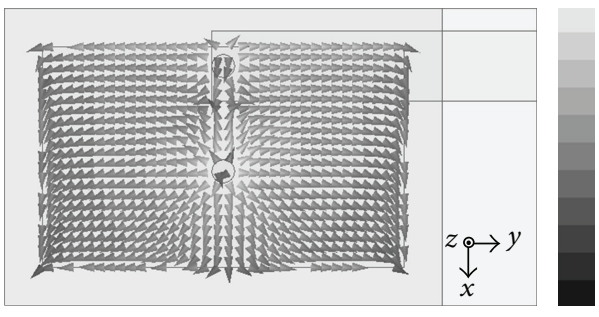

$2.0000 e+001$ $1.1101 e+001$ $6.1616 e+000$ छ $3.4200 e+000 \longleftarrow$ $1.8982 e+000$ $1.0536 e+000$ $5.8480 e-001 \exists$ $3.2459 e-001-$ $1.8016 e-001$ $1.0000 e-001$

FIGURE 10: Simulated current distribution on the top patch of the antenna at $2.45 \mathrm{GHz}$.

adopted, as shown in Figure 14 [21]. The implanted microstrip antenna (port 1) is located just under the subcutaneous fat of the left chest. The proposed antenna (port 2) is placed $10 \mathrm{~mm}$ above the left chest surface.

Figure 15 shows the comparison between the simulated $S$ parameter characteristics of the six-sided phantom shown in Figure 12 and those of the Duke model shown in Figure 14. Overall, the simulated results of the six-sided phantom are in good agreement with those of the Duke model.

Figure 16 shows the simulated far-field radiation patterns of the proposed antenna with the Duke model at $2.45 \mathrm{GHz}$ in the $x z$-and $y z$-planes. The maximum gain of the antenna is $1.5 \mathrm{dBi}$. The proposed antenna with the Duke model has a monopole-like radiation pattern in the $2.45 \mathrm{GHz}$ ISM band.

Figure 17 shows the simulated average specific absorption rate (SAR) distribution normalized to the maximum SAR (input power: $1 \mathrm{~W}$ ) of the proposed antenna with the Duke model. The American National Standards Institute requires that the SAR values should be below $1.6 \mathrm{~W} / \mathrm{kg}$ over a volume of $1 \mathrm{~g}$ of tissue. The maximum SAR values are $17.92 \mathrm{~W} / \mathrm{kg}$ at $2.45 \mathrm{GHz}$ and $134 \mathrm{~W} / \mathrm{kg}$ at $5.8 \mathrm{GHz}$ (1g tissue). To satisfy the SAR limitation (1.6 W/kg for partial-body exposure), the input power should be below $89.29 \mathrm{~mW}$ at $2.45 \mathrm{GHz}$ and $11.94 \mathrm{~mW}$ at $5.8 \mathrm{GHz}$ [22].

The simulation results of this study were obtained using HFSS based on the finite-element method and the SEMCAD $\mathrm{X}$ based on the finite-difference time-domain method [23, 24].

\section{Experimental Results}

The configurations of the proposed antenna and the fabricated two-third muscle-equivalent phantom $(200 \mathrm{~mm} \times$ $200 \mathrm{~mm} \times 70 \mathrm{~mm}$ ) for the measurement setup are shown in Figure 18. Because the manufactured phantom does not have dispersive permittivity and conductivity, it has only a single value in all frequencies. Therefore, we fabricated phantoms 


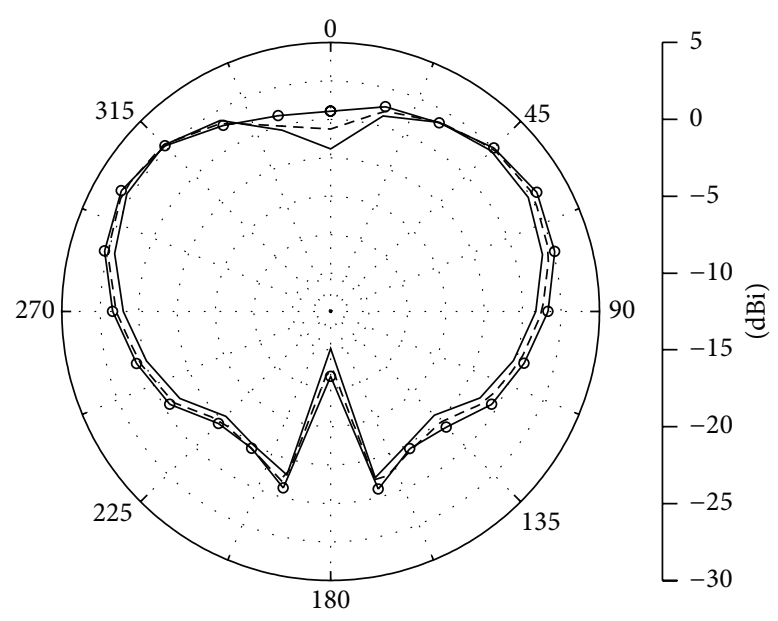

$\begin{aligned}- & \text { Gap }=5 \mathrm{~mm} \\ -- & \text { Gap }=10 \mathrm{~mm} \\ \rightarrow & \text { Gap }=15 \mathrm{~mm}\end{aligned}$

(a)

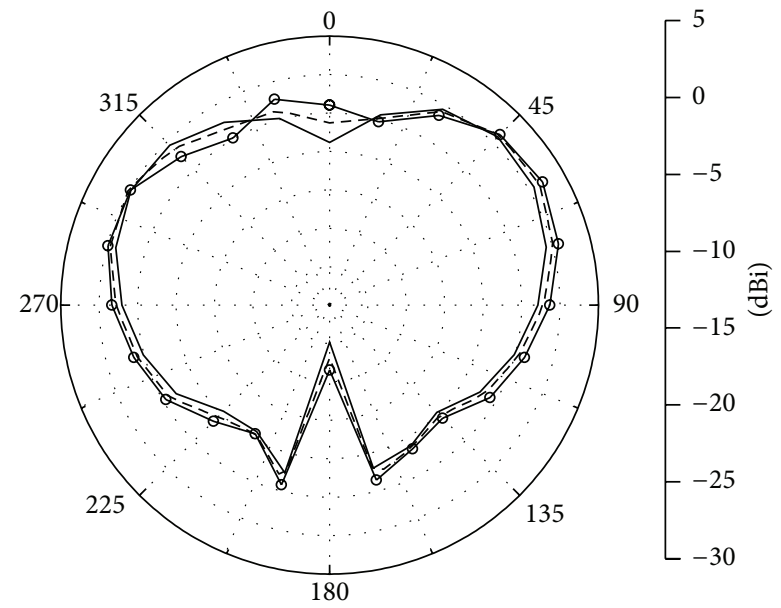

$\begin{aligned} \text { - Gap } & =5 \mathrm{~mm} \\ ---\mathrm{Gap} & =10 \mathrm{~mm}\end{aligned}$

$\rightarrow$ Gap $=15 \mathrm{~mm}$

(b)

FIGURE 11: Radiation patterns of the proposed antenna for various gap distances $(d)$ at the $2.45 \mathrm{GHz}$ ISM band. (a) $x z$-plane. (b) $y z$ plane.

for 2.45 and $5.8 \mathrm{GHz}$ separately to validate the antenna performance in the two frequency bands. The electrical properties and ingredients of the two-third muscle-equivalent phantoms $[7,18,25]$ at the 2.45 and $5.8 \mathrm{GHz}$ ISM bands are summarized in Table 1.

Figure 19 shows the measured and simulated $S_{11}$ characteristics of the proposed antenna on the phantom $(d=$ $10 \mathrm{~mm}$ ). For the measurement, the phantom for $2.45 \mathrm{GHz}$ was used from 2 to $3 \mathrm{GHz}$ and that for the $5.8 \mathrm{GHz}$ was used from 5.2 to $6.4 \mathrm{GHz}$. The measured $10 \mathrm{~dB}$ impedance bandwidths of the antenna were $8.5 \%(2.37-2.58 \mathrm{GHz})$ in the $2.45 \mathrm{GHz}$ ISM band and 7.1\% (5.6-6.01 GHz) in the 5.8 GHz ISM band.

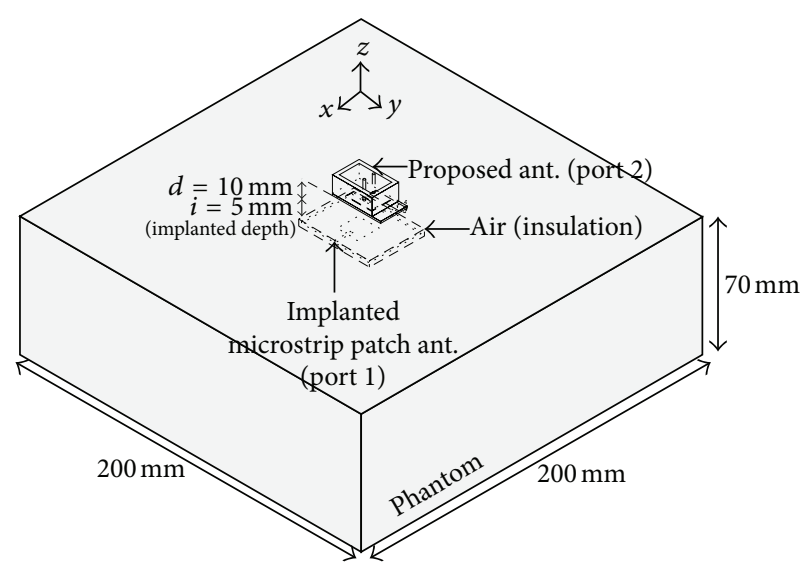

FIGURE 12: Isometric view of the simulation setup for the in-on communication between the implanted microstrip patch antenna in the phantom and the proposed antenna on the phantom.

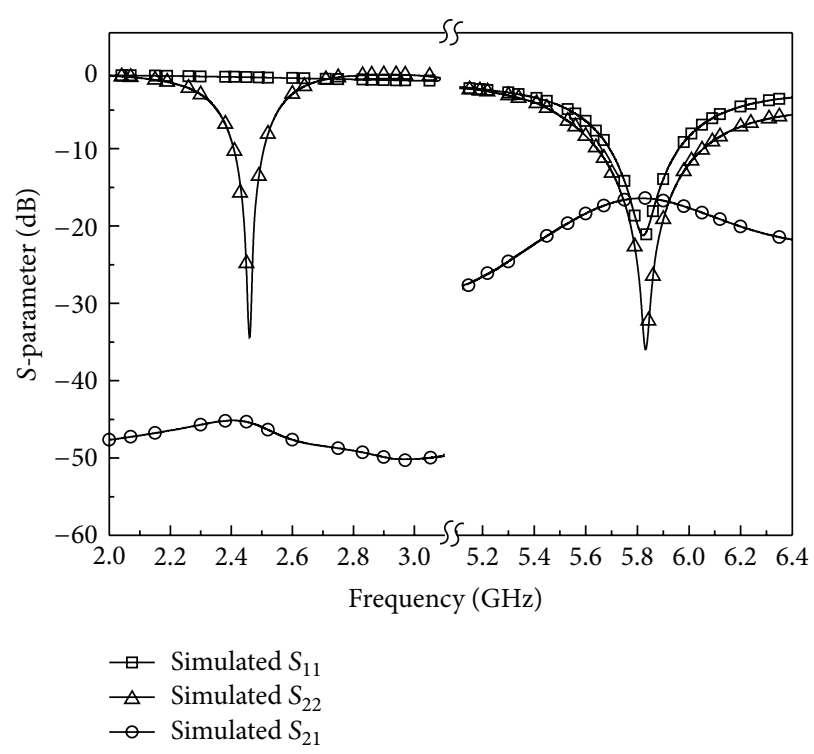

FIgURE 13: Simulated $S$-parameter characteristics of the in-on communication between the implanted microstrip patch antenna in the phantom and the proposed antenna on the phantom (port 1: implanted microstrip antenna; port 2: proposed antenna).

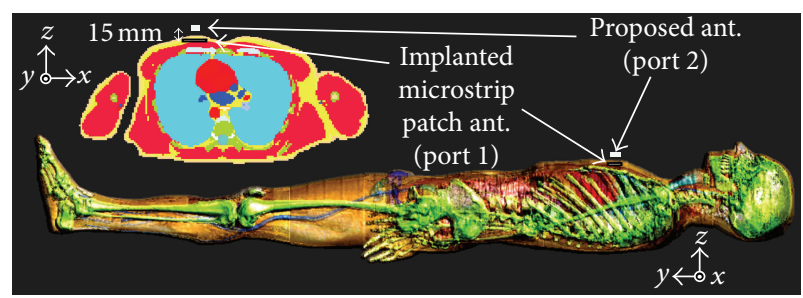

FIgURE 14: Simulation setup with the Duke model for verification of the proposed antenna in practical environment (port 1: implanted microstrip antenna; port 2: proposed antenna). 


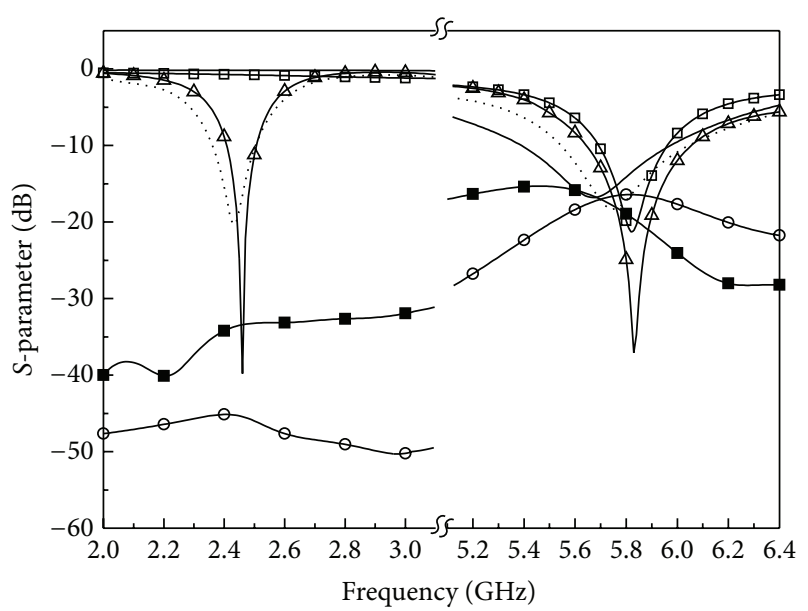

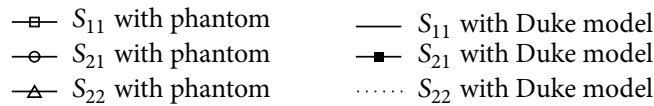

FIGURE 15: Comparison between the simulated $S$-parameter characteristics of the six-sided phantom and those of the Duke model (port 1: implanted microstrip antenna; port 2: proposed antenna).

TABLE 1: Electrical properties and ingredients of the two-third muscle-equivalent phantoms.

\begin{tabular}{lcc}
\hline \multirow{2}{*}{ Ingredient } & \multicolumn{2}{c}{ Composition ratio (\%) } \\
& $\begin{array}{c}2.45 \mathrm{GHz} \text { ISM band } \\
\left(\varepsilon_{r}=35.5, \sigma=1.2 \mathrm{~S} / \mathrm{m}\right)\end{array}$ & $\begin{array}{c}2.45 \mathrm{GHz} \text { ISM band } \\
\left(\varepsilon_{r}=35.5, \sigma=1.2 \mathrm{~S} / \mathrm{m}\right)\end{array}$ \\
\hline $\begin{array}{l}\text { Deionized } \\
\text { water }\end{array}$ & 59.7 & 74.07 \\
$\begin{array}{l}\text { Polyethylene } \\
\text { powder }\end{array}$ & 14.92 & 22.22 \\
Agar & 2.98 & 3.7 \\
Glycerin & 20.89 & - \\
TX-151 & 1.49 & - \\
\hline
\end{tabular}

${ }^{*}$ Measurement temperature: $26^{\circ} \mathrm{C}$.

Overall, the simulated result was in good agreement with the measurement result. The discrepancy between the simulated and measured results may have been due to manufacturing error of the three-layer fabricated antenna and inaccuracy of the phantom size.

Figure 20 shows the simulated and measured radiation patterns of the proposed antenna on the phantom when $d=10 \mathrm{~mm}$. The measured results agree reasonably well with the simulated results. The proposed antenna has a minimum radiation normal to the phantom surface and maximum radiation tangent to the phantom surface at $2.45 \mathrm{GHz}$. The measured peak gain of the proposed antenna on the phantom was $1.27 \mathrm{dBi}$. The measured radiation efficiency of the proposed antenna without the phantom was $61.92 \%$ at $2.45 \mathrm{GHz}$ and $71.74 \%$ at $5.8 \mathrm{GHz}$ and that of the proposed antenna with the phantom was $36.75 \%$ at $2.45 \mathrm{GHz}$ and $75.76 \%$ at $5.8 \mathrm{GHz}$.

In this work, the proposed antenna is designed for the $5.8 \mathrm{GHz}$ ISM band in-on communication with lowdepth implantable device such as a pacemaker implanted in the subcutaneous fat. Therefore, far-field analysis is not necessary to evaluate the in-on communication performance in this region. To verify the simulated result for the inon communication, a microstrip patch antenna operating in the $5.8 \mathrm{GHz}$ ISM band for implanted device was fabricated, as shown in Figure 21. The manufactured microstrip patch antenna has a unidirectional radiation pattern suitable for inon communication.

Figure 22 shows the simulated and measured $S$-parameter characteristics of the in-on communication between the implanted microstrip patch antenna in the phantom and the proposed antenna on the phantom. In the measurement, a polystyrene foam was adopted as insulating air for the implanted antenna. Some discrepancies exist in the $S_{21}$. However, the overall trend of the measured $S$-parameters is in good agreement with that of the simulation. All results were obtained using the Agilent E8358A Network Analyzer.

\section{Analysis of Body-Movement Effect}

4.1. Received Signal Power at Various Antenna Locations. The received signal power on the on-body antennas depends on the antenna locations and body postures. To investigate the body effect on the received signal power, a channel measurement activity was conducted for various on-body antenna locations and human movements in the $2.45 \mathrm{GHz}$ ISM band. The received signal power $\left(S_{21}\right)$ at the on-body receiver was measured using a vector network analyzer, and a human body (height $=180 \mathrm{~cm}$ and weight $=90 \mathrm{~kg}$ ) inside an anechoic chamber was used. A transmitter (Tx) antenna was placed on the left chest, and receive $(\mathrm{Rx})$ antennas were placed on the head, chest, stomach, thigh, and arm. Three human movements, namely, standing, walking, and sitting up and down, were considered. For each movement and antenna location, the received power was measured for $10 \mathrm{~s}$.

Table 2 shows the means and variances of the received signal power at various receiver positions and for different body postures. For human movements such as walking and sitting down and up, the signal power variance is larger than that for steady posture such as standing still. The received signal power values measured over $10 \mathrm{~s}$ at different $\mathrm{Rx}$ antenna positions are plotted in Figure 23. The received signal power is the strongest at the chest antenna, which is closest to the Tx antenna. In contrast, the thigh antenna shows the weakest received signal power because its distance from the Tx antenna is the longest. The proposed antenna shows the received signal power following our expectation under the WBAN settings.

4.2. Channel Capacity for Various Body Movements at Fixed Antenna Location. The channel capacity was also computed to evaluate the measured channels. The channel capacity is given by

$$
C=\log _{2}(1+\mathrm{SNR}),
$$

where SNR is the signal-to-noise ratio, which is determined by the received signal power/noise power. A noise power of $-90 \mathrm{dBm}$ was obtained from the measurement. 


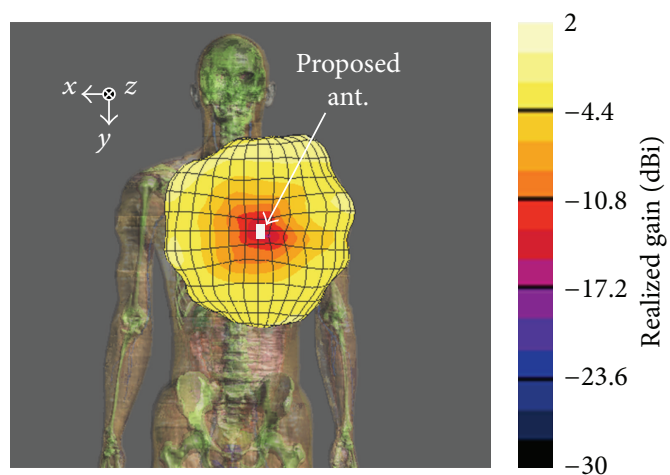

(a)

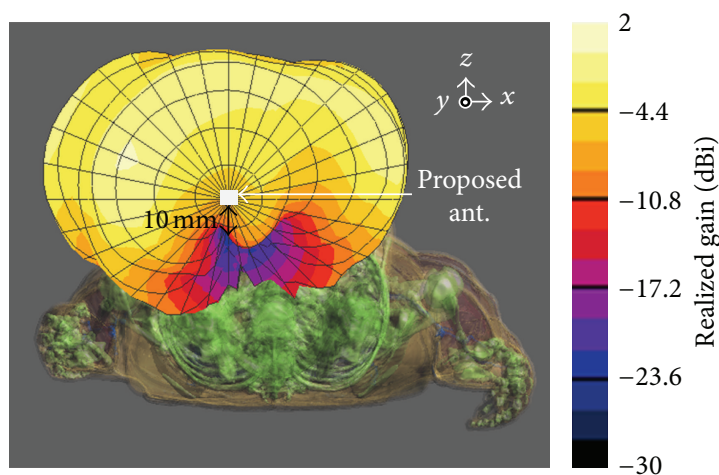

(b)

FIGURE 16: Radiation patterns of the proposed antenna with the Duke model at the $2.45 \mathrm{GHz}$ ISM band. (a) $x y$-plane. (b) $x z$-plane.

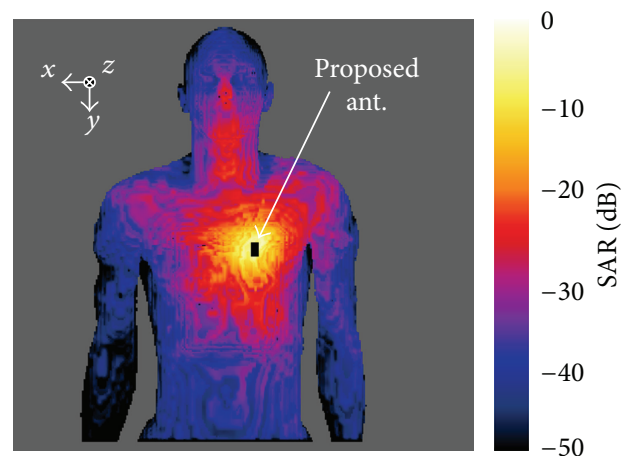

(a)

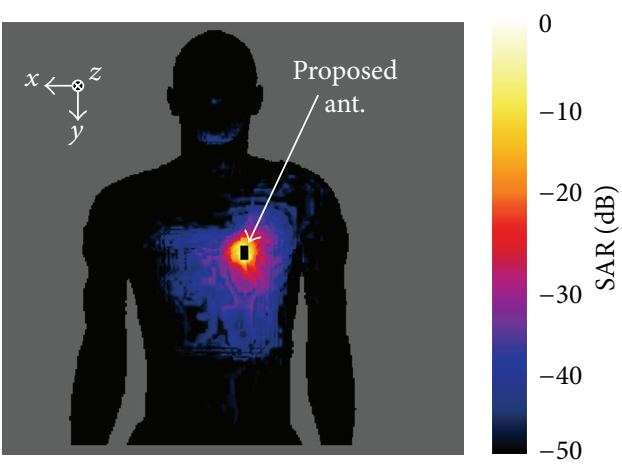

(b)

FIGURE 17: Simulated average SAR distribution of the proposed antenna with the Duke model (decibel normalized to the maximum SAR; input power: $1 \mathrm{~W}$ ). (a) $2.45 \mathrm{GHz}$ (maximum SAR: $17.92 \mathrm{~W} / \mathrm{kg}$ ). (b) $5.8 \mathrm{GHz}$ (maximum SAR: $134 \mathrm{~W} / \mathrm{kg}$ ).

TABLE 2: Received power for various receiver positions and body postures.

\begin{tabular}{lccc}
\hline & Standing & Walking & Sitting down and up \\
\hline Arm & & & -54.7935 \\
Average & -57.4785 & -58.2443 & 1.6766 \\
Dispersion & 1.0192 & 6.5225 & -40.9304 \\
Chest & & & 1.0493 \\
Average & -37.8377 & -40.1259 & 0.7348 \\
Dispersion & 0.1022 & & -50.5486 \\
Head & & -53.8702 & 1.8158 \\
Average & -53.8209 & 9.9121 & -40.1617 \\
Dispersion & 0.7318 & -40.0269 & 2.0912 \\
Stomach & & 0.6043 & -45.0382 \\
Average & -41.5824 & & 8.9139 \\
Dispersion & 0.0786 & -54.0026 & 3.7319 \\
Thigh & & & \\
Average & -61.0783 & 2.8965 & \\
Dispersion & & & \\
\hline
\end{tabular}

${ }^{*}$ Unit: dBm. 


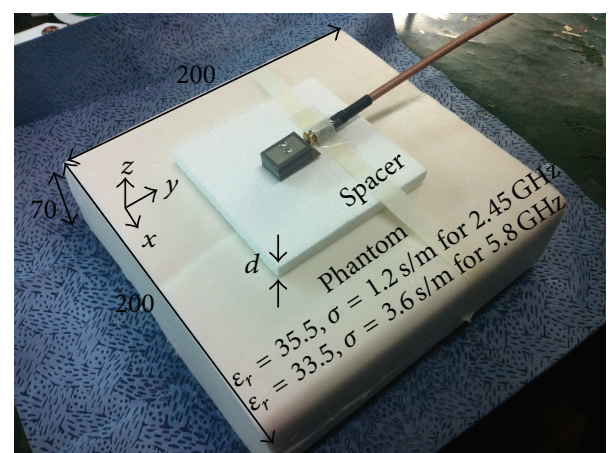

FIGURE 18: Fabricated antenna and two-third muscle-equivalent phantom for the measurement setup $(d=10 \mathrm{~mm})$. The phantom for the $2.45 \mathrm{GHz}$ ISM has $\varepsilon_{r}=35.5$ and $\sigma=1.3 \mathrm{~S} / \mathrm{m}$ and that for the $5.8 \mathrm{GHz}$ ISM has $\varepsilon_{r}=33.2$ and $\sigma=3.6 \mathrm{~S} / \mathrm{m}$.

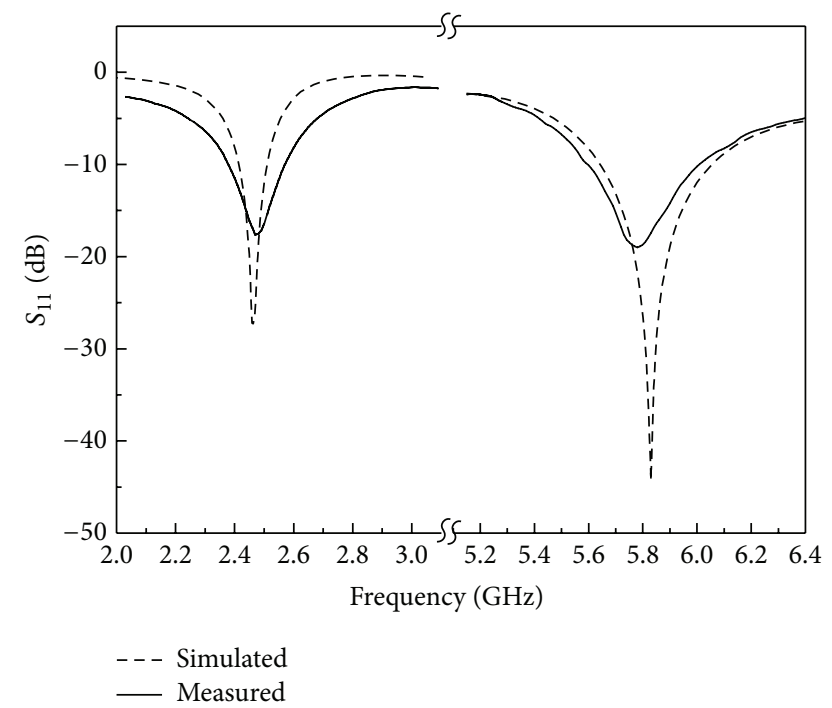

FIGURE 19: Measured and simulated $S_{11}$ characteristics of the proposed antenna on the phantom $(d=10 \mathrm{~mm})$.

Figures 24(a) and 24(b) show the cumulative density functions (CDFs) of the measured channel capacities for the three body movements at the chest and thigh. On average, the chest, which receives the strongest signal power, yields the largest channel capacity whereas the thigh, which has a weak received power, shows the smallest channel capacity. Figure 24 shows that, at a fixed antenna position, different human movements result in different channel capacities because the human movements cause variations in the $\mathrm{Tx}$ $\mathrm{Rx}$ antenna separation and in the propagation conditions. Figure 24(b) shows that sitting up and down results in better channel capacity than standing still because the sitting movements shorten the Tx-Rx distance.

4.3. Probability Distribution Fitting. The empirical cumulative distribution function (CDF) for each antenna position and body posture was calculated from the normalized data. Several reference theoretical models (Nakagami- $m$, Rician, Gamma, and Weibull) were compared with the empirical

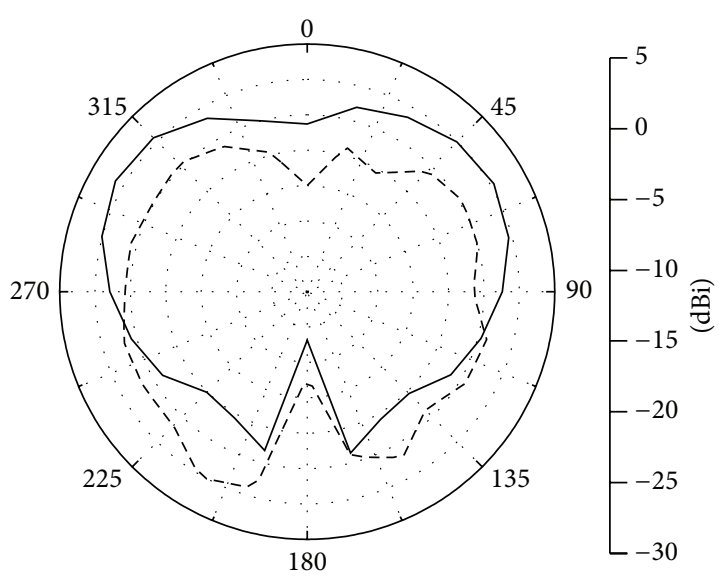

- Simulated

- - - Measured

(a)

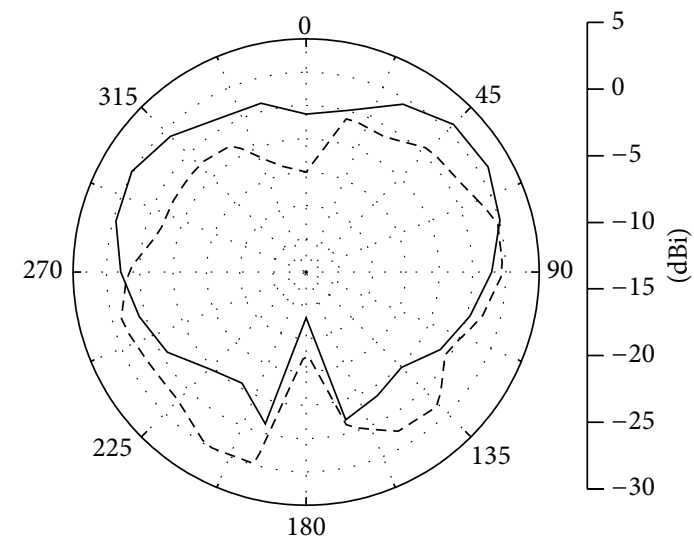

- Simulated

- - - Measured

(b)

FIGURE 20: Simulated and measured radiation patterns of the proposed antenna on the phantom at $2.45 \mathrm{GHz}(d=10 \mathrm{~mm})$. (a) $x z$ plane. (b) $y z$-plane.

CDFs using the Kolmogorov-Smirnov fit test (KS test) to determine the best fit distribution. This test calculates the maximal distance between the numerical data and the theoretical model data. The KS statistic is defined as [26]

$$
D=\max _{x}\left|F_{E}(x)-F_{X}(x)\right|,
$$

where $F_{E}$ is the $\mathrm{CDF}$ of the measured data and $F_{X}$ is the CDF of the theoretical distribution.

The distribution that provides the best fit in each case is the one with the lowest KS statistic. Table 3 shows the best fit model for each case, which fits the single branch envelope. In most cases, the fading models in each scenario follow the Weibull fading models. However, that of the antenna attached to the thigh follows the Nakagami and Gamma fading model. The Rician fading model shows the worst case in all measured data fitting. 


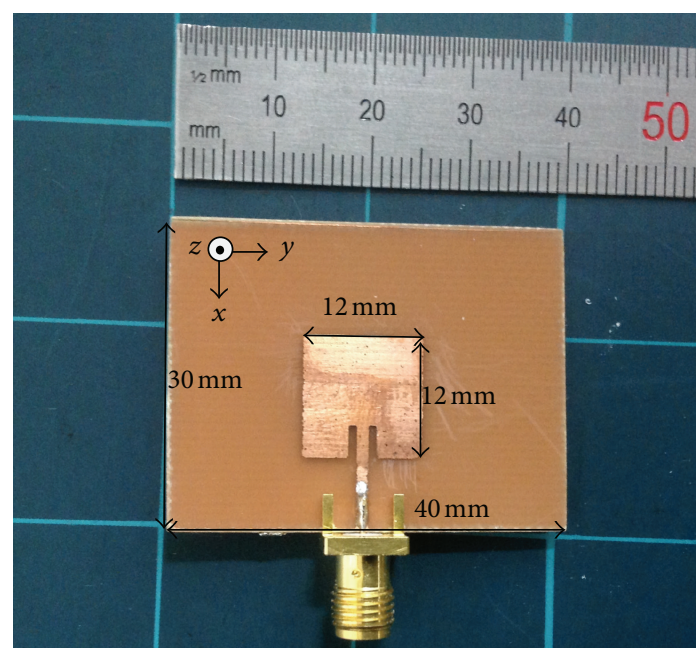

FIGURE 21: Geometry of the microstrip patch antenna for the implanted device operating in the $5.8 \mathrm{GHz}$ ISM band for in-on communication measurement.

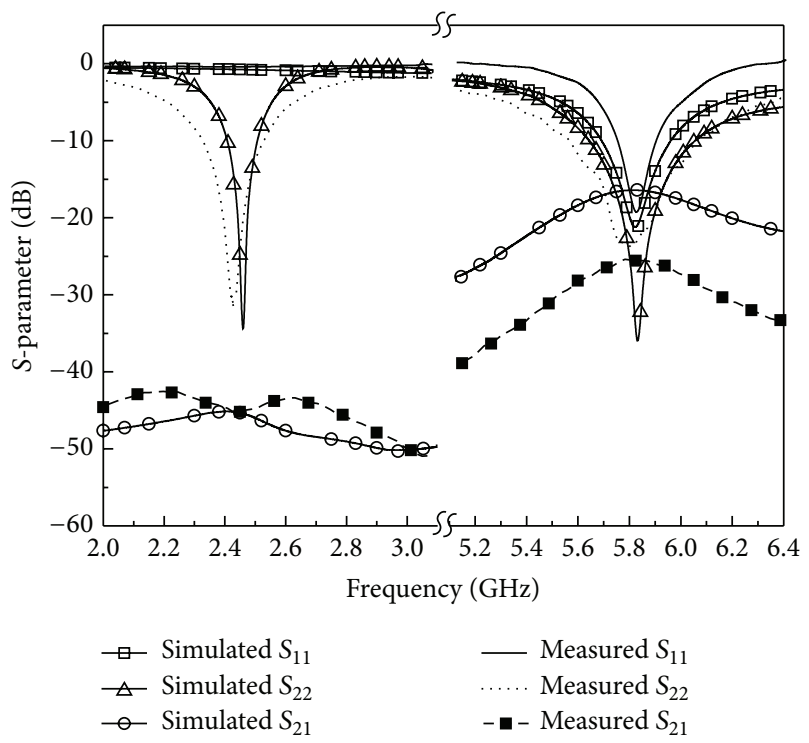

FIGURE 22: Simulated and measured $S$-parameter characteristics of the in-on communication between the implanted microstrip patch antenna in the phantom and the proposed antenna on the phantom as shown in Figure 10 (port 1: implanted microstrip antenna; port 2: proposed antenna).

\section{Conclusion}

A dual-band on-body repeater antenna for in-on-on WBAN applications has been proposed. The simulated and measured $10 \mathrm{~dB}$ impedance bandwidths were sufficient to cover the required frequency bands $(2.45 \mathrm{GHz}$ ISM band $(2.4-2.485 \mathrm{GHz})$ and $5.8 \mathrm{GHz}$ ISM band $(5.725-5.825 \mathrm{GHz}))$. The proposed antenna provides a dipole-like radiation pattern for on-on body communication in the $2.45 \mathrm{GHz}$ ISM band and a directional radiation pattern for the in-on body communication in the $5.8 \mathrm{GHz}$ ISM band. To verify these properties, phantoms for 2.45 and $5.8 \mathrm{GHz}$ were fabricated

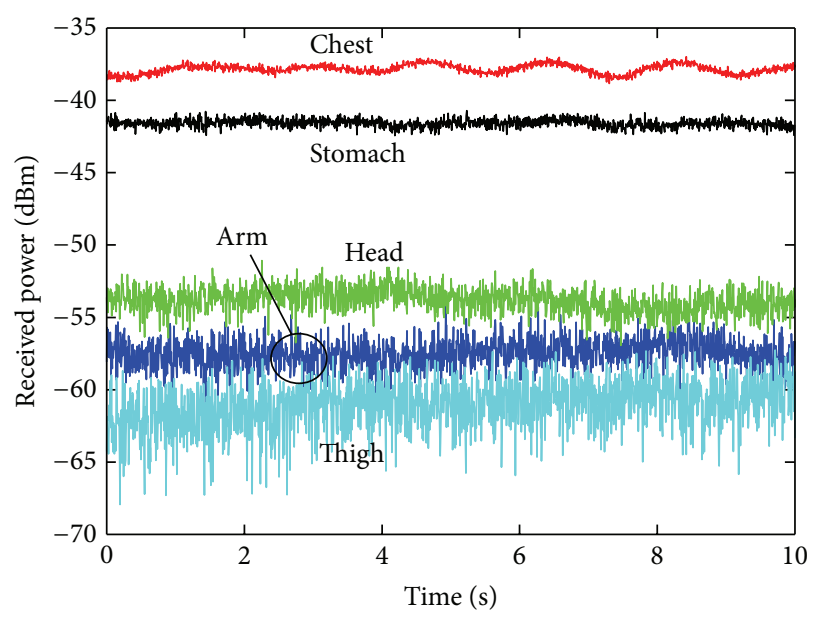

FIGURE 23: Measurement of received signal power comparison at the receiver position in standing posture.

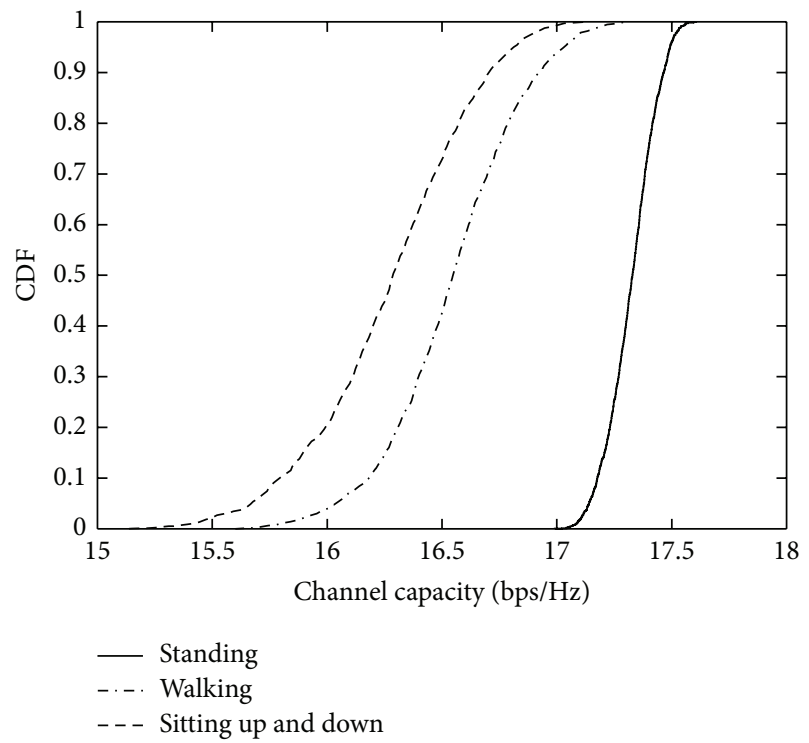

(a) Chest

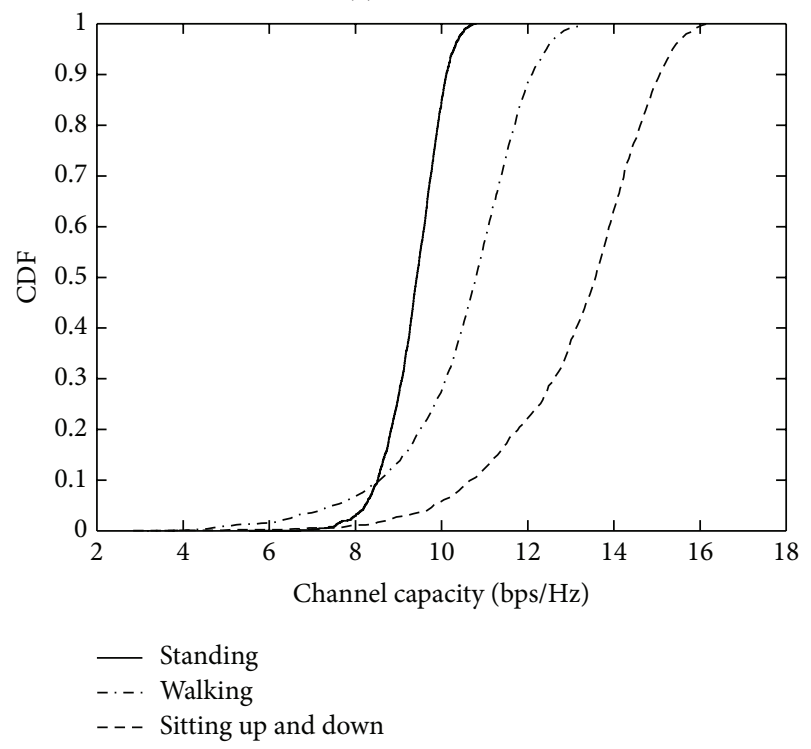

(b) Thigh

FIGURE 24: CDFs of the measured channel capacity comparison for various body postures for (a) chest and (b) thigh. 
TABLE 3: Best fit distribution and estimated parameters for each measurement scenario.

\begin{tabular}{|c|c|c|c|c|c|}
\hline \multirow{2}{*}{ Antenna position and body posture } & \multirow{2}{*}{ Best fit } & \multicolumn{4}{|c|}{ Envelope } \\
\hline & & Nakagami & Rician & Gamma & Weibull \\
\hline \multicolumn{6}{|l|}{ Arm } \\
\hline Standing & $\mathrm{W}$ & 0.5926 & 0.6523 & 0.5059 & 0.0403 \\
\hline Walking & G & 0.0127 & 0.0368 & 0.0039 & 0.9116 \\
\hline Sitting up and down & $\mathrm{W}$ & 0.3249 & 0.3943 & 0.2461 & 0.0218 \\
\hline \multicolumn{6}{|l|}{ Chest } \\
\hline Standing & $\mathrm{W}$ & 0.621 & 0.621 & 0.5913 & 0.0789 \\
\hline Walking & $\mathrm{W}$ & 0.9942 & 0.9968 & 0.9904 & 0.0039 \\
\hline Sitting up and down & $\mathrm{W}$ & 0.5332 & 0.5915 & 0.4772 & 0.1124 \\
\hline \multicolumn{6}{|l|}{ Head } \\
\hline Standing & $\mathrm{W}$ & 0.9643 & 0.9912 & 0.9457 & 0.0246 \\
\hline Walking & $\mathrm{W}$ & 0.6525 & 0.8733 & 0.4515 & 0.1233 \\
\hline Sitting up and down & $\mathrm{W}$ & 0.3937 & 0.4713 & 0.3244 & 0.0114 \\
\hline \multicolumn{6}{|l|}{ Stomach } \\
\hline Standing & $\mathrm{W}$ & 0.9567 & 0.9428 & 0.9428 & 0.002 \\
\hline Walking & $\mathrm{N}$ & 0.0001 & 0.0369 & 0.0245 & 0.1323 \\
\hline Sitting up and down & G & 0.0018 & 0.002 & 0.0011 & 0.2187 \\
\hline \multicolumn{6}{|l|}{ Thigh } \\
\hline Standing & G & 0.073 & 0.1234 & 0.0413 & 0.8747 \\
\hline Walking & G & 0.8025 & 0.7979 & 0.001 & 0.0024 \\
\hline Sitting up and down & $\mathrm{N}$ & 0.001 & 0.009 & 0.004 & 0.1834 \\
\hline
\end{tabular}

${ }^{*}$ W: Weibull; G: Gamma; N: Nakagami.

and used to measure the antenna performance. A channel measurement activity was conducted to investigate the effect of human-body movements and antenna locations. We have demonstrated that the proposed antenna can be effectively deployed on a human body to allow WBAN applications such as in a medical self-monitoring system owing to its dual-band characteristic and desirable field distributions.

\section{Acknowledgments}

This research was supported in part by the Korea Communications Commission (KCC), Republic of Korea, under the $\mathrm{R} \& \mathrm{D}$ program supervised by the Korea Communications Agency (KCA) KCA-2013-11911-01109, and in part by the National Research Foundation of Korea (NRF) Grant funded by the Korean government (MEST) (no. 2012-0005655).

\section{References}

[1] P. S. Hall and Y. Hao, Antennas and Propagation for Body-Centric Wireless Communications, chapter 1, Artech House, Norwood, Mass, USA, 2006.

[2] Y. Rahmat-Samii and J. Kim, Implanted Antennas in Medical Wireless Communications, chapter 1, Morgan \& Claypool Publishers, San Rafael, Calif, USA, 2006.

[3] M. R. Kamarudin, Y. I. Nechayev, and P. S. Hall, "Performance of antennas in the on-body environment," in Proceedings of the IEEE Antennas and Propagation Society International Symposium and USNC/URSI Meeting, vol. 3A, pp. 475-478, Washington, DC, USA, July 2005.
[4] C. A. Balanis, Antenna Theory: Analysis and Design, pp. 27-32, chapter 1, Wiley-Interscience, New York, NY, USA, 3rd edition, 2005.

[5] P. S. Hall, Y. Hao, Y. I. Nechayev et al., "Antennas and propagation for on-body communication systems," IEEE Antennas and Propagation Magazine, vol. 49, no. 3, pp. 41-58, 2007.

[6] K.-L. Wong and C.-I. Lin, "Characteristics of a $2.4 \mathrm{GHz}$ compact shorted patch antenna in close proximity to a lossy medium," Microwave and Optical Technology Letters, vol. 45, no. 6, pp. 480-483, 2005.

[7] C. H. Lin, K. Saito, M. Takahashi, and K. Ito, "A compact planar inverted-F antenna for $2.45 \mathrm{GHz}$ on-body communications," IEEE Antennas and Propagation Society, vol. 60, no. 9, pp. 44224426, 2012.

[8] C. Delaveaud, P. Leveque, and B. Jecko, "New kind of microstrip antenna: the monopolar wire-patch antenna," IEEE Electronics Letters, vol. 30, no. 1, pp. 1-2, 1994.

[9] G. A. Conway and W. G. Scanlon, "Antennas for over-bodysurface communication at $2.45 \mathrm{GHz}$," IEEE Transactions on Antennas and Propagation, vol. 57, no. 4, pp. 844-855, 2009.

[10] J. Liu, Q. Xue, H. Wong, H. W. Lai, and Y. Long, "Design and analysis of a low-profile and broadband microstrip monopolar patch antenna," IEEE Transactions on Antennas and Propagation, vol. 61, no. 1, pp. 11-18, 2013.

[11] A. Al-Zoubi, F. Yang, and A. Kishk, "A broadband center-fed circular patch-ring antenna with a monopole like radiation pattern," IEEE Transactions on Antennas and Propagation, vol. 57, no. 3, pp. 789-792, 2009.

[12] D. Guha and Y. M. M. Antar, "New half-hemispherical dielectric resonator antenna for broadband monopole-type radiation," IEEE Transactions on Antennas and Propagation, vol. 54, no. 12, pp. 3621-3628, 2006. 
[13] R. Khouri, P. Ratajczak, P. Brachat, and R. Staraj, "A thin surfacewave antenna using a via-less EBG structure for $2.45 \mathrm{GHz}$ on-body communication systems," in Proceedings of the 4th European Conference on Antennas and Propagation (EuCAP '10), Barcelona, Spain, April 2010.

[14] F. Yang, Y. Rahmat-Samii, and A. Kishk, "Low-profile patch-fed surface wave antenna with a monopole-like radiation pattern," IET Microwaves, Antennas and Propagation, vol. 1, no. 1, pp. 261266, 2007.

[15] Z. G. Liu and Y. X. Guo, "Dual band low profile antenna for body centric communications," IEEE Transactions on Antennas and Propagation, vol. 61, no. 4, pp. 2282-2285, 2013.

[16] A. A. Serra, A. R. Guraliuc, P. Nepa, G. Manara, I. Khan, and P. S. Hall, "Dual-polarisation and dual-pattern planar antenna for diversity in body-centric communications," IET Microwaves, Antennas and Propagation, vol. 4, no. 1, pp. 106-112, 2010.

[17] K. Kwon, J. Ha, S. Lee, and J. Choi, "Design of a dual-band onbody antenna for a wireless body area network repeater system," International Journal of Antennas and Propagation, vol. 2012, Article ID 350797, 5 pages, 2012.

[18] C. Gabriel, "4-Cole-Cole analysis on compilation of the dielectric properties of body tissues at RF and microwave frequencies," Brooks Air Force Tech. Rep. AL/OE-TR-1996-0037, 1996, http://www.fcc.gov/fcc-bin/dielec.sh.

[19] W. Hong, B. Liu, Y. Q. Wang et al., "Half mode substrate integrated waveguide: a new guided wave structure for microwave and millimeter wave application," in Proceedings of the 31st International Conference on Infrared and Millimeter Waves and 14th International Conference on Terahertz Electronics (IRMMWTHz '06), p. 219, Shanghai, China, September 2006.

[20] R. Garg, P. Bhartia, I. Bahl, and A. Ittipiboon, Microstrip Antenna Design Handbook, pp. 441-463, chapter 7, Artech House, Norwood, Mass, USA, 2001.

[21] A. Christ, W. Kainz, E. G. Hahn et al., "The virtual familydevelopment of surface-based anatomical models of two adults and two children for dosimetric simulations," Physics in Medicine and Biology, vol. 55, no. 2, pp. N23-N38, 2010.

[22] "IEEE standard for safety levels with respect to human exposure to radio frequency electromagnetic fields, $3 \mathrm{kHz}$ to $300 \mathrm{GHz}$," IEEE Standard C95, pp. 1-1999, 1999.

[23] HFSS, "High Frequency Structure Simulator Based on Finite Element Method," v. 15.0, ANSYS Corp., 2013.

[24] X. Semcad, A FDTD-Based Electromagnetic Simulator, version 14.6.9 Bernina, Schmid \& Partner Engineering AG, Zurich, Switcherland, 2013.

[25] S. Lee, W. Seo, K. Kwon, and J. Choi, "The study on implementation of a semi-solid flat phantom with equivalent electrical properties to whole human body at MICS and ISM band," The Korean Institute of Electromagnetic Engineering \& Science, vol. 23, no. 1, pp. 101-107, 2012.

[26] A. Michalopoulou, A. A. Alexandridis, K. Peppas et al., "Onbody channel statistical analysis based on measurements in an indoor environment at $2.45 \mathrm{GHz}$," IET Microwaves Antennas and Propagation, vol. 6, pp. 636-645, 2012. 

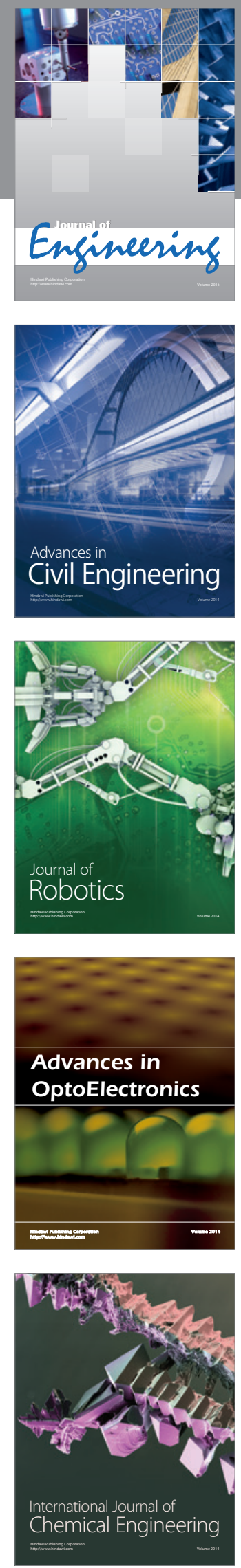

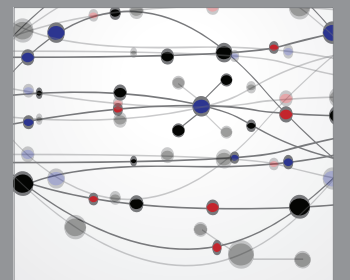

The Scientific World Journal
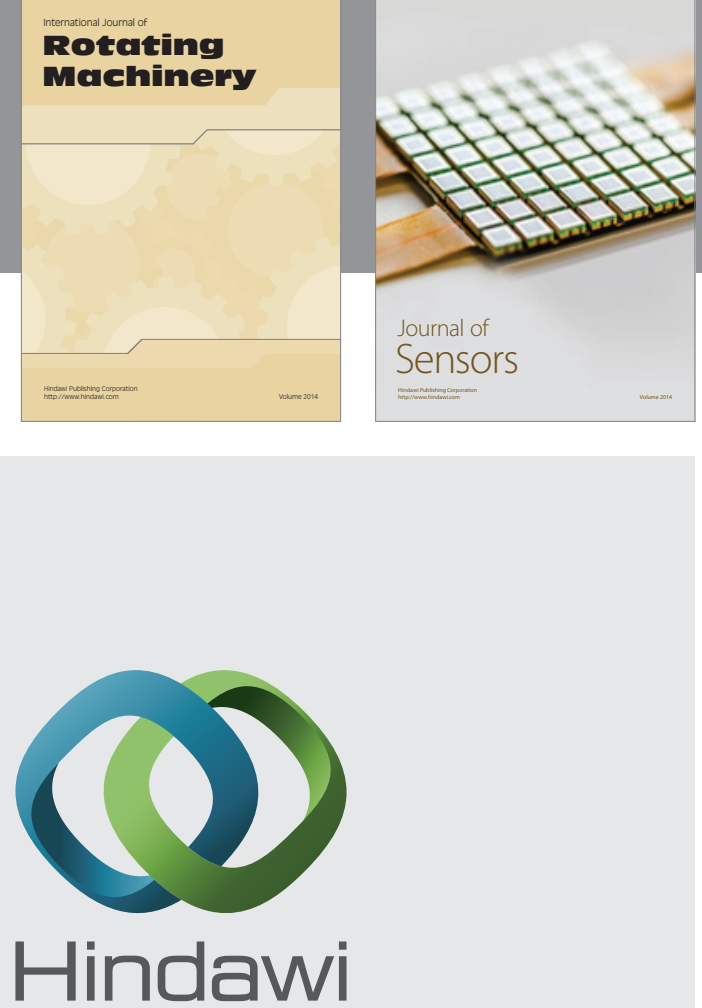

Submit your manuscripts at http://www.hindawi.com
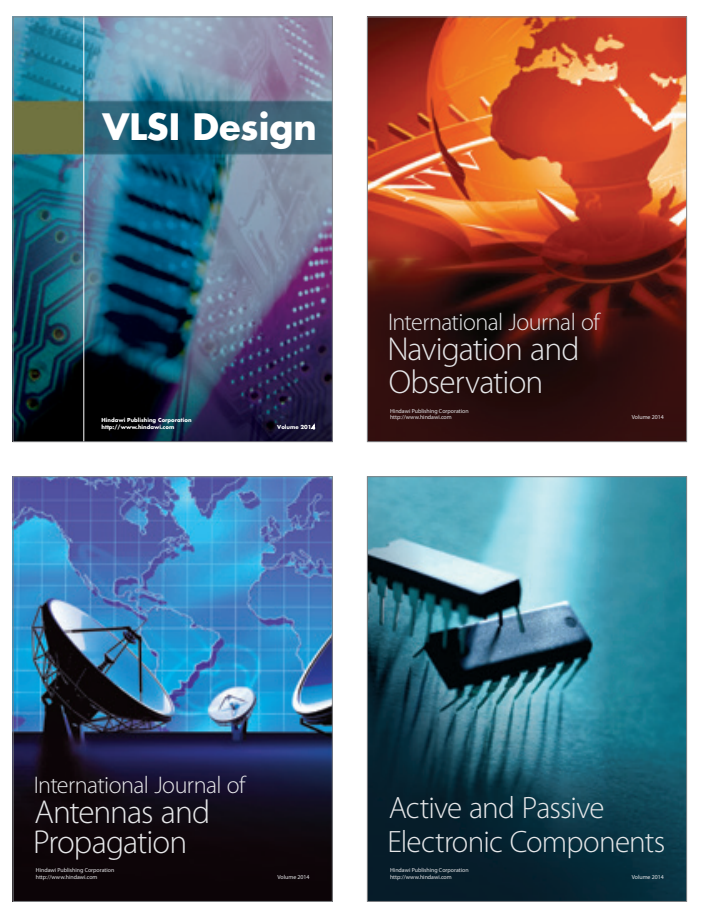
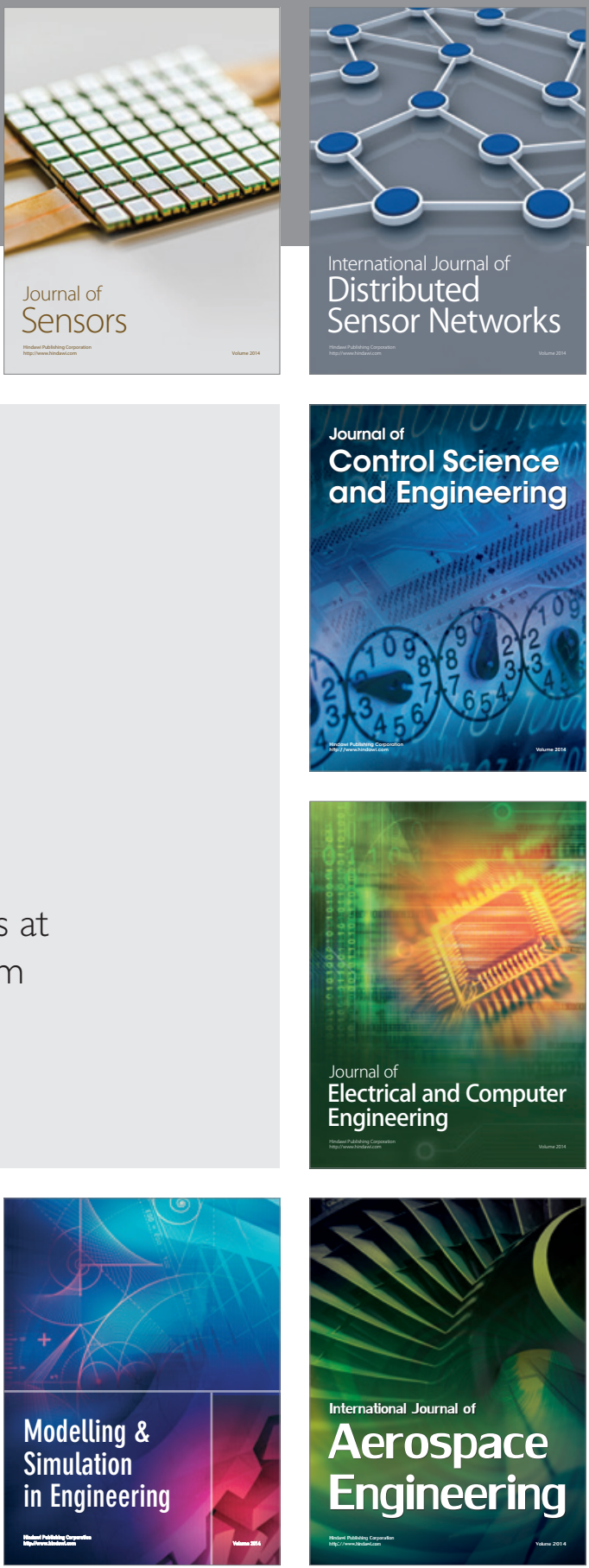

Journal of

Control Science

and Engineering
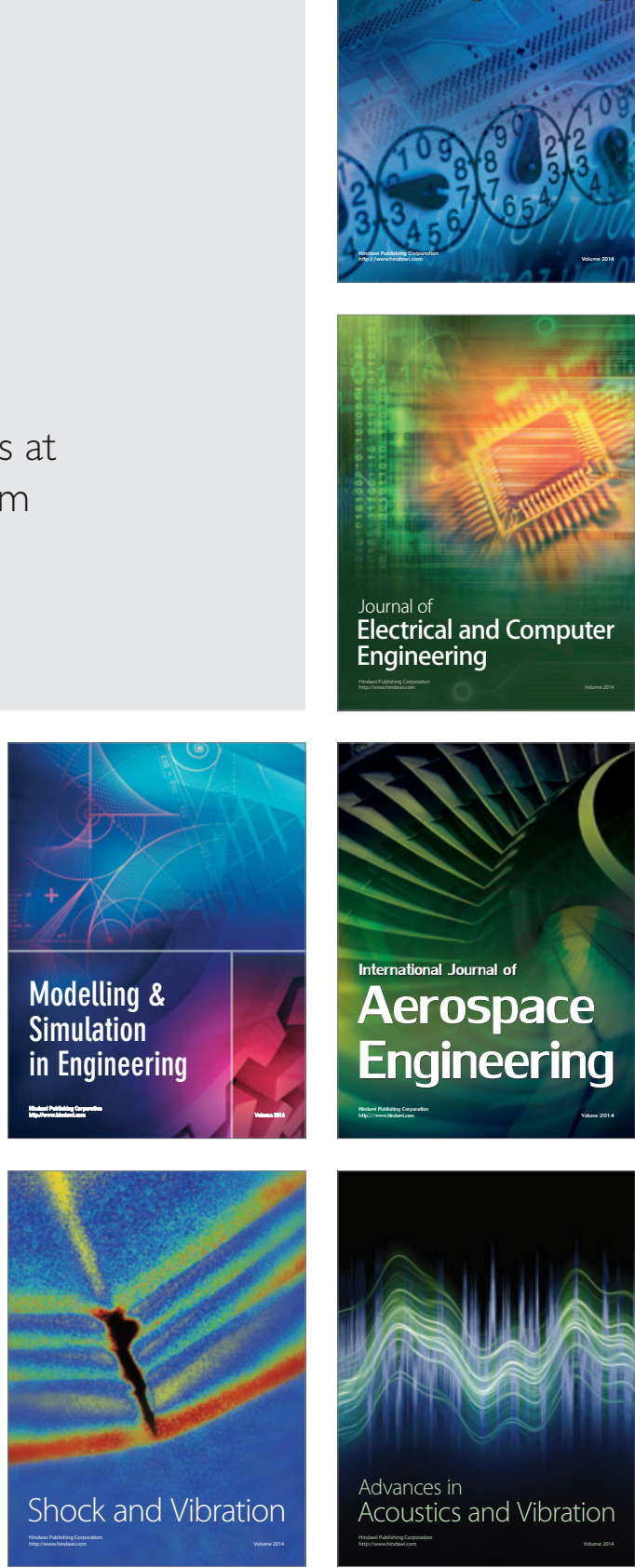